DOI: $10.5216 / \mathrm{hr} . v 15 i 1.10820$

\title{
A Leitura e a Vida: O teXto E OS LEITORES de Monteiro Lobato*
}

Fabiana de Souza Fredrigo**

fabianafredrigo@yahoo.com.br

Resumo: Este artigo pretende acompanhar as transformações das práticas culturais contemporâneas, com atenção especial para as atividades de leitura e de elaboração de textos. Nesse sentido, a obra infantil de Monteiro Lobato servirá de guia para essa discussão, com a avaliação de dois escritos do referido autor: Memórias de Emília, de 1939, e A Reforma da Natureza, de 1941.

Palavras-Chave: Monteiro Lobato, História, Literatura, Leitura.

O homem imaginou uma cidade perdida na memória e a repetiu tal como se lembra. O real não é o objeto da representação, mas o espaço em que se dá um mundo fantástico (PIGLIA, 2006, p. 12).

Prólogos

"Isso de começar não é fácil. Muito mais simples é acabar. Pinga-se um ponto final e pronto; ou então escreve-se um latinzinho: FINIS. Mas começar é terrível” (Lовато, 2002, p. 10). Assim Monteiro Lobato anuncia as dificuldades da boneca de pano em começar suas memórias. Inquisitiva e esperta, Emília assusta o impoluto Visconde, o seu escrevente, quando lhe ordena iniciar o texto de "suas" memórias "botando" seis pontos de interrogação - seis pontos, nem um a mais, nem um a menos. Tinha lógica na cabeça da boneca tal começo, afinal, ao escrever memórias, ela interrogava a si mesma.

\footnotetext{
* Uma versão resumida deste texto foi apresentada no 1o. Salão do Livro Infantil e Juvenil de Goiás, evento realizado em abril de 2008, que homenageou Monteiro Lobato. Essa informação justifica a linguagem utilizada em algumas passagens deste artigo.

** Professora da Faculdade de História da Universidade Federal de Goiás.
} 
Desde que aceitei o convite para retornar às obras infantis de Monteiro Lobato, busquei me reencontrar com a criança que as leu e assistiu às adaptações para a televisão. Dessa maneira, é importante sublinhar o objetivo que norteia a minha escrita: a pretensão é explicitar o percurso de uma leitora de Lobato, apontando questões sobre leitura e elaboração de textos, que me parecem pertinentes à obra desse autor. As dificuldades quanto à definição do percurso foram muitas, pois bem se sabe que o reencontro com a criança que leu e assistiu às aventuras do Sítio do Picapau Amarelo, embora possa ser mediado pela memória, guarda armadilhas. O que quero dizer é que reler Lobato, hoje, não me concede o conhecimento de como lia Lobato antes. Nesse sentido, há um problema inerente ao apontamento anterior, qual seja: a investigação em torno do procedimento envolvido na análise da percepção e da recepção da leitura. Em outras palavras: apreender a leitura infantil ou adulta é sempre tarefa árdua; embora, para o caso de Monteiro Lobato, seja possível utilizar como fonte as numerosas cartas recebidas de crianças leitoras. Como se a problemática em torno da recepção fosse pequena, há que se ter ciência de que as histórias bem podem ser muitas, têm muitos caminhos, têm muitas verdades desconexas, isso tudo para desgosto dos historiadores, de quem Emília faz troça. A boneca lembra que é preciso mentir com muita manha para que os leitores possam acreditar que se trata de uma "verdade pura" - e os historiadores, em sua nada modesta opinião, devem ser atrapalhados, ludibriados, já que são "gente muito mexeriqueira".

Essa discussão sobre começos tem um sentido: anotar a dificuldade de abordar Lobato, não apenas por conta das variadas polêmicas que esse homem causou em vida, das múltiplas facetas que assumiu e das muitas empreitadas nas quais se envolveu, mas também por conta da extensão de tinta e papel dedicada a esse autor. Não restam dúvidas quanto ao fato de que esse escritor "resiste a enquadramentos e adjetivações generalizantes" (LuCA, 2005, p. 139). Definitivamente, Lobato nunca foi unanimidade, embora sua obra infantil encontrasse entre as crianças uma acolhida certeira. Aliás, talvez por isso mesmo ele não fosse unanimidade, pois os adultos divergiam sobre o "formar" e o "educar", enquanto Lobato, em seus livros, apresentava sua própria pedagogia. Nessa toada, cabe acrescentar que as muitas pesquisas sobre esse autor trouxeram uma série de considerações que, provavelmente, serão repetidas neste artigo. Enfim, tratar de Lobato é, sem dúvida, correr o risco de se repetir, mas, ainda assim, é um exercício profícuo e prazeroso retornar à obra infantil desse autor.

Muitas justificativas poderiam ser transcritas para responder o questionamento sobre a validade em abordar Lobato. Entendo que a biografia 
desse literato por si só justifica e legitima a escolha, se ressaltarmos as ligações íntimas desse paulista com a intelectualidade que lhe foi contemporânea basta registrar seus contatos com os modernistas e os nomes da literatura infanto-juvenil argentina, nos anos de 1940 - e, ainda, a variedade e a importância de suas polêmicas políticas, capazes de lhe render uma prisão durante o Estado Novo. Todavia, para esse artigo, a justificativa fundamental pode ser resumida da seguinte forma: Monteiro Lobato foi responsável pela formação de comunidades de leitores, desse modo, avaliar sua escritura colabora para a compreensão das práticas culturais contemporâneas. Por fim, ultrapassada a longa lista de justificativas e aceitas as dificuldades de se abordar a obra infantil lobatiana, lembrei-me de um conto de Clarice Lispector, que, dentre outros, genuinamente, é uma homenagem ao escritor Lobato e à leitura. Esse sim é um bom começo: acompanhar a angústia de uma criança ávida por ler.

Expressamente autobiográfico, o conto de Clarice Lispector, Felicidade Clandestina (1998), nos apresenta uma menina "gorda, baixa, sardenta e de cabelos crespos arruivados", que sabia ser cruel como ninguém com as outras meninas, as "imperdoavelmente bonitinhas, esguias, altinhas, de cabelos livres". Essa informação inicial, que nos remete imediatamente às primeiras artimanhas do universo infantil em sua aprendizagem relacional, é complementada pelo dado de que a menina cruel tinha como pai um dono de livraria - era esse o dado que lhe permitia exercitar, com calma e ferocidade, o sadismo. As humilhações da narradora foram muitas em nome do seu desejo de ter acesso aos livros que a menina, filha de dono de livraria, sequer se interessava em ler. Para uma, o livro e a leitura eram puro deleite, para a outra, o livro servia - tão somente - de instrumento facilitador para exposição do ressentimento. De repente, em meio ao universo de conformidade, Clarice Lispector nos apresenta "o livro" causador de maior humilhação: Reinações de Narizinho. Casualmente, como se quisesse "praticar tortura chinesa", a garotinha ruiva anunciou possuir o livro de Lobato, inacessível para muitas outras meninas da escola, dentre elas a narradora. Fez mais: disse que poderia emprestá-lo, caso a menina esbelta passasse pela sua casa no dia seguinte. A criança, desejosa em ler o novo livro de Lobato, transformou-se, então, na "própria esperança da alegria". E, assim, transformada, ia dia-a-dia fazer uma visita à colega, que sempre lhe respondia o mesmo: Ah! O livro acabou de ser emprestado, que pena! Volte amanhã.

O conto continua, num tempo indefinido, retratando a angústia e o desejo da menina pelo livro de Monteiro Lobato. Aquela criança, que vislumbrava as possibilidades infinitas do universo lobatiano, não se rendeu facilmente e, 
graças à sua insistência e esperança sempre renovadas, foi salva pelo aparecimento da mãe da garota sardenta, isso depois de muitos dias de vigília à porta da casa. Rapidamente, a mãe se inteirou do plano diabólico da filha e impediu sua sequência, informando à narradora que ela podia levar o livro emprestado (que nunca saíra da casa) pelo "tempo que quisesse". Se a espera pela leitura fora vivenciada num tempo longo, quase interminável, o horizonte que se abria com a frase daquela mãe significou para a criança o êxtase, não sendo possível sequer contar em detalhes o que se seguiu. A narradora nos informa ter saído andando devagarzinho, muito diferente de seu jeito de andar, que era pulando pelas ruas do Recife. Informa também que não leu o livro de pronto, como poderia? Não, estabeleceu todo um jogo com a possibilidade de leitura: fingia que não tinha o livro, escondia-o para achá-lo em seguida, inventava outros afazeres para atrasar a leitura, como comer pão com manteiga, lia um pouquinho, só um pouquinho, e o fechava. Depois de longa espera, o conto termina, sem uma linha de "avaliação ou crítica da leitura". Ao contrário, de forma sugestiva, a escritora anota: "Às vezes sentava-me na rede, balançandome com o livro aberto no colo, sem tocá-lo, em êxtase puríssimo. Não era mais uma menina com um livro: era uma mulher com o seu amante" (LISPECTOR, 1998, p. 11-2).

É impossível não deixar que a força da escrita de Clarice Lispector nos invada e, invadidos, partilhemos com a autora de um desejo perdido, lá na infância, por um livro que, por muito pouco, não foi lido. Da mesma forma, é difícil não recorrer à memória e indagar sobre aquele livro, "o livro" que nos formou. Quando, rapidamente, faço o caminho da memória, Monteiro Lobato aparece seguido de Maria José Dupré, com o inesquecível cachorrinho Samba e sua turma - não casualmente a mesma Sra. Dupré, cuja literatura provocou boa surpresa em Lobato, quando leu o romance Éramos Seis (SOARES, 2007, p. 207-8 $)^{1}$. Como a memória é astuta para emendar presente e passado e, portanto, não se apresenta "tal como foi", mas "tal como nos lembramos", mais do que a história em detalhes, o que me vem com a lembrança desses livros é a sensação de prazer imenso em tê-los lido, é a felicidade de ter comprado o livro para deixar marcas nos trechos que mais apreciara - com livro de biblioteca bem sabemos não poder cometer tal imprudência.

Fruto mais das sensações provocadas pela leitura do que da longa e lenta elaboração intelectual sobre o que foi lido, a lembrança me leva a considerar, sem muita restrição, que o estilo literário assumido por esses escritores fazia toda a diferença, sendo uma obrigação curvar-se ao prazer da leitura. Essa consideração reporta-me, novamente, ao conto de Clarice Lispector, muito particularmente ao seu final, que me parece ser a homenagem mais bela 
à obra infantil de Lobato: a metáfora que faz a personagem passar do livro ao homem recoloca a literatura em seu lugar. Aquela literatura, a de Lobato, era pura vida, capaz de encher a menina de expectativas, assim como o amante fazia com a mulher. Num contraponto às mesmices das leituras patrióticas (LAJOLO; ZilbERMAN, 1984), que demarcavam a literatura infanto-juvenil da primeira hora republicana, os livros de Lobato eram os livros com os quais se experimentava uma felicidade clandestina, atrasando a leitura, deixando o melhor para o final, dormindo, sonhando.

Com estilo próprio e boa aceitação no universo infantil, ainda assim, é preciso sublinhar que Lobato não nasceu sabendo a "fórmula" que encantaria as crianças. Em concordância com Cilza Bignotto (2007), é importante demarcar a constante (re) construção da obra lobatiana, cujo caso mais notável é a reescrita de vários textos que compõem Reinações de Narizinho. Ainda mais interessante é a exposição da autora sobre um conto de Lobato para crianças, "D’après Nature". No referido conto, da linguagem à exploração da temática, há pouquíssima semelhança com o saudado Sítio (a não ser a referência à desobediência infantil), estando o escrito mais próximo dos contos de Olavo Bilac, Coelho Neto, Júlia Lopes de Almeida, dentre outros. Por sua vez, Gabriela Soares anota que, diferente do que ocorrerá no universo do Sítio, "nos contos para adultos, a imaginação das personagens infantis, tolhida pelo mundo exterior, não pode transbordar. Serve de refúgio para a alma da criança, ajuda-a a definir sua identidade, mas não a livra dos desenlaces trágicos que a vida real lhes impõe [...]" (SOARES, 2007, p. 177).

Enfim, o Sítio aparece como uma novidade, capturando o espírito e as vontades infantis. Afinal, não é muito difícil imaginar o quão prazeroso seria morar no Sítio do Picapau Amarelo, de posse do pó de Pirlimpimpim, podendo comer todos os bolinhos de tia Nastácia, sem nunca ter sono para não correr o risco de perder um pedacinho sequer das maravilhosas histórias de Dona Benta - histórias que ela ora lia, histórias que ora ela contava "com suas próprias palavras", mesmo que amparada pelo livro. Dona Benta é a personagem que provoca o desejo pela leitura porque sabe como contar as histórias para os netos. Nesse sentido, a avó é a representação da mediação entre a tradição oral e a cultura letrada, assumindo a função "pedagógica", à moda de Lobato: ao alimentar a imaginação das crianças, forma futuros e entusiasmados leitores. De sua parte, esses futuros entusiasmados leitores seriam, também, homens ávidos por todo tipo de conhecimento que a leitura primeira de Lobato fornecia sem muita delonga.

É unânime entre os leitores e os intérpretes da obra de Lobato o fato de que o Sítio era um lugar para se viver - um lugar em que o "real" e a 
“imaginação" conviviam de forma rocambolesca. A passagem inaudita de uma cena adaptada à realidade à outra, mais consoante com o mundo dos sonhos, antes de incomodar, trazia conforto. Aliás, trazia mais: trazia desejo vívido de estar no livro, estabelecendo entre leitor e livro um pacto indissolúvel, mediado pelo desejo. Morar no Sítio, passar uma temporada com os netos de Dona Benta, aproveitar para um dia conversar com o Visconde ou se aventurar pela mata próxima com o Saci eram situações que povoavam o cotidiano infantil.

A esse respeito, é ilustrativa uma passagem de O Picapau Amarelo, de 1939, comentada por Marisa Lajolo. A autora reporta-se à cena em que, ao discutir sobre literatura com outros personagens lendários, Dom Quixote reclama do fato de Cervantes tê-lo criado como o "via em sua imaginação" e não como ele era "na realidade". Segundo a autora, a cena divertidíssima provoca no leitor um segundo de hesitação, pois "pode comprometer sua certeza de que nada nos livros é realidade, tudo é ficção. D. Quixote, Emília, D. Benta, Belerofonte e Capitão Gancho são igualmente personagens" (LAJOLO, 2007, p. 3). A conclusão da autora é que o espaço ficcional do Sítio obriga o leitor a "pisar devagarinho nos estreitos limites de fantasia e realidade" (LAJOLO, 2007, p. 3). O mais interessante é que a criança formada por esse tipo de leitura acaba por encantar-se com o universo infinito das passagens (da realidade à ficção e vice-versa) e as encara com naturalidade, tal como faz em seu dia-a-dia. Em virtude disso, a criança reconhece no universo literário uma operação que lhe é familiar, identificando-se com a leitura. O leitor de Monteiro Lobato terá de aceitar a deliciosa condição de entrar num jogo em que a mistura entre "realidade" e a "ficção" faça-o questionar, inclusive, a estrita separação entre "verdade" e "mentira", afinal, como dirá Emília, "verdade é uma espécie de mentira bem pregada, das que ninguém desconfia. Só isso" (LOBATO, 2002, p. 8).

Colocadas as questões iniciais, interessa-me, nesse curto espaço de tempo, chegar ao "como": como problematizar o processo por meio do qual a leitura conforma interpretações e estabelece universos. Esse caminho de investigação me chama a atenção não porque queira apresentar a "receita" para inocular nos pequenos o desejo de ler. As perguntas sobre o ato de ler e como ler pretendem alcançar considerações sobre como a literatura humaniza (CANDIDo, 1999), deixando claro que a humanização vem da capacidade literária em "fazer viver". Cabe, rapidamente, anotar que a associação entre literatura e humanização não pretende estabelecer critérios de diferença entre os textos promotores de reflexão e auto-aprimoramento e os textos não promotores de reflexão e auto-aprimoramento. Para Abreu (2006), essa 
associação, em algumas circunstâncias, é feita para criar e legitimar cânones (a "Grande Literatura"), subjazendo, na associação, uma crítica à cultura de massa, como se a transformação e a humanização, advindas por meio do ato de ler, estivessem restritas à lista dos clássicos escolhidos pelos críticos literários. Segundo a autora, posição com a qual concordo, um best seller pode muito bem servir à humanização. Nesse caso, a associação entre literatura e humanização serve para se referir à leitura que nos toca, nos transforma e, nesse sentido, nos "forma", muito mais do que nos "educa" - isso se tomarmos como "educar" o pressuposto de um ato de aprendizagem que faz da leitura apenas um meio para incorporar as regras cultas da língua. Durante sua carreira de escritor e interessado nos caminhos da educação infantil, Lobato se indispôs com esse modo de ensinar e de usar a leitura, fazendo de seus livros infantis o lugar de uma pedagogia própria.

Ir ao encontro de um texto e poder tomar posse dele, construindo seu próprio universo interpretativo, mesmo considerando os limites da tarefa, são ações que permitem ao leitor sentir o apelo da vida. Tal como nos alerta Chartier (1999), é preciso guardar que ler é apropriar-se, é inventar, é subverter. Ao mesmo tempo em que o leitor pode parecer amarrado às intenções do autor, pois as astúcias daquele que conta uma história podem ser muitas, ele dialoga com o que lê para, em seguida, construir sua história, daí o ditado popular que diz: "quem conta um conto, aumenta um ponto" - quem lê, ao apropriar-se da leitura e reinventá-la, faz o mesmo. Somos leitores e contadores de histórias, embora deva se considerar que as práticas de leitura estão recortadas por princípios próprios (temporais e sociais) às distintas comunidades leitoras (CHARTIER, 1999). Se, de um lado, as comunidades leitoras universalizam o assim considerado patrimônio cultural partilhado, do outro, cada leitor, membro da comunidade, pode imaginar com a (e a partir da) história que é narrada, pode misturar a história contada a outras ouvidas ou lidas em momentos distintos, pode, ainda, mesclar as histórias com as suas memórias. Enfim, de um "texto" nascem outros numerosos textos e a avaliação dos leitores depende sempre do grau de seu envolvimento com a temática, na medida em que o texto colocará em xeque princípios, olhares, convicções e valores (ABREU, 2006).

Literatos e historiadores conhecem o poder da literatura e a sua capacidade de formar, mas historiadores, por seu turno, têm muita dificuldade em apreender o "como" desse processo - se é que ele pode ser apreendido. Cada vez mais interessados na relação que pode ser estabelecida entre História e Literatura, bem como nos meandros da história da leitura, os historiadores estabeleceram ampla polêmica para tratar da temática em torno da elaboração 
de um texto. Duas perguntas em particular instigam os pesquisadores: será possível apreender "as vidas" que produziram o texto, considerando que um texto deixa de ser propriedade de seu autor no exato momento da primeira leitura? Como apreender, sobretudo, a memória que instituiu tal texto na categoria de "partilha universal"? Como tratar da questão da recepção da leitura? Em suma, como se procede à avaliação dessas interrogações, sem apreender a literatura como "instrumento" a serviço das respostas necessárias?

Ainda, em outras palavras, posso resumir da seguinte forma a intriga: Emília faz troça dos historiadores enxeridos, ao mesmo tempo em que, implicitamente, aponta a literatura como um universo onde várias verdades cabem - inclusive as que colocam o "real" de ponta-cabeça, misturando-o com a fantasia. A propósito do desrespeito da boneca de macela com os historiadores, é preciso considerar que a História, irmã enciumada da Literatura, ressente-se em não conseguir se apropriar da chave preciosa da humanização, pois esperou, por longo tempo, que ela viesse por meio do horizonte da "verdade científica".

Particularmente, o nó se encontra na necessidade de afirmação do status científico da produção dos historiadores. Guardado por longo tempo, o temor quanto à aproximação da História ao campo literário esteve vinculado à crítica da escola metódica direcionada à forma e ao estilo da escrita dos historiadores, que "buscavam preencher os espaços vazios deixados pela fragmentação dos vestígios com 'lendas', 'conjecturas sem fundamento’ ou 'raciocínios fundados em generalizações imprudentes'” (BERBERT JR., 2007, p. 42). Reaproximar os campos da História e da Literatura, cuidando bem de suas fronteiras, é um desafio que provoca ansiedade e preocupação, posto que a festejada interdisciplinaridade não é objetivo tão simples de ser alcançado. Não obstante, é importante registrar o esforço dos historiadores nesse sentido, o que tem provocado complexa discussão no campo da Teoria da História. Por fim, a chave da humanização não se relaciona apenas à liberdade que a obra literária experimenta quando pode "inventar verdades com manha", mas, sobretudo, aos limites impostos ao texto histórico, que se vê obrigado a tomar como espúria sua antiga relação com a retórica (BERBERT JR., 2005). Como campos que têm necessidade de demarcar fronteiras, os limites do texto histórico revelam que os historiadores formulam um tipo diferenciado de consciência, que tem a "verdade" como horizonte para adentrar no território desconhecido do passado, daí a preocupação com o método de aproximação das fontes. Enfim, História e Literatura passaram a delimitar suas fronteiras, fazendo com que arte e ciência se desvinculem para apreender a "vida", sempre maior que as duas. 
Partindo das reflexões expostas, discutirei as questões em torno da leitura, usando, sempre que possível, os textos de Lobato como guia. Pretendo aproximar-me de uma reflexão que permita, simultaneamente, anotar as transformações alusivas às práticas culturais contemporâneas e desvendar a preocupação de Monteiro Lobato com a tessitura de seus escritos.

\section{LEITURA, LEITORES E OUTRAS PRÁTICAS CULTURAIS CONTEMPORÂNEAS}

Há variados caminhos para se abordar a relação entre leitura e vida. Colocarei alguns problemas que me parecem anunciar uma possibilidade de reflexão sobre a constante e apavorante máxima em torno da afirmação de que os leitores jovens escasseiam, dia-a-dia. Embora as estatísticas não permitam contrariar absolutamente esse fato, o que interessa é matizar o "catastrofismo" e compreender as transformações alusivas às práticas de representação cultural contemporâneas. Cada vez mais, o fundamental é alcançar o conhecimento sobre essas práticas, suas apropriações e, mais particularmente, a formação das comunidades de leitores ${ }^{\mathrm{b}}$. Para um público que se interessa em despertar a curiosidade e a imaginação para abastecer o mundo de leitores, talvez seja importante anunciar, imediatamente, que nós todos somos ávidos pelas histórias, especialmente as contadas por e para todos, pois as histórias nos levam a partilhar as aspirações capazes de construir e sedimentar o "sentido de comunidade" (CALLIGARIS, 2004, p. 58). Assim, podemos todos ficar tranquilos: para boas histórias, sempre teremos bons ouvintes e ouvintes cativos têm muita chance de se tornarem leitores entusiasmados.

Segundo Nelson Schapochnik (2005), os diagnósticos sombrios a respeito da finitude dos objetos sustentadores da cultura letrada assemelham-se às reações provocadas quando do advento da imprensa. Do mesmo modo, Jean Lebrun, em entrevista concedida a Chartier (1999), nos lembra que a comparação entre a revolução eletrônica e a revolução de Gutenberg é comum, mesmo considerando que um livro manuscrito dos séculos XIV e $\mathrm{XV}$, por exemplo, e um livro pós-Gutenberg guardam a mesma estrutura. $\mathrm{O}$ anterior não impediu, à época, a persistência de uma forte suspeita diante do impresso, entendendo que ele seria responsável pelo afastamento entre autores e leitores, com o rompimento da familiaridade construída entre ambos. Ao final das contas, essa ação reativa indica que "as mudanças no padrão tecnológico de comunicação alteram as práticas e as representações culturais" (SCHAPOCHNIK, 2005, p. 10). O que devemos fazer é nos tranquilizar, na medida do possível, quanto à alteração dessas práticas, visto que essa ação parece-me inevitável. 
As rápidas transformações contemporâneas perturbaram, inclusive, nossa experimentação do tempo. De um lado, Nicolau Sevcenko, apoiandose no filósofo Hans Jonas, nos adverte sobre o presentismo. Segundo esses autores, o caráter cumulativo das inovações tecnológicas transformou nossa relação com o tempo. Esse processo, o presentismo, permite "assumir decisões que envolvem grandes riscos no presente, sem considerar suas consequências e vítimas futuras" (SEVCENKO, 2001, p. 45). O impacto da incorporação de tal lógica não interfere apenas na economia (com a devastação do meio ambiente, a escassez dos recursos e o acréscimo da exploração do trabalho), mas modifica nossa concepção em relação à Ética e à História. Do outro, Calligaris (2004) comenta o prevalecimento dos afazeres imediatos, com o sumiço dos projetos coletivos em longo prazo. O futuro encolheu, engoliu a utopia, pois a agenda do dia é deveras extenuante. Assim, trata-se mesmo de uma nova experiência do tempo, em que sentidos para viver coletivamente vêm sendo profundamente reformulados.

Essas mesmas transformações nos obrigaram a conviver com distintas linguagens de representação: do livro passamos ao cinema, do cinema passamos à televisão e da televisão ao computador. Todos esses meios responsáveis pelas práticas culturais contemporâneas, uns mais, outros menos, nunca abandonaram a necessidade de burilar a palavra, apesar de se constatar que o caso do livro eletrônico aponta para "uma revolução nas estruturas do suporte material do escrito assim como nas maneiras de ler" (CHARTIER, 1999, p. 13). Ainda assim, a afirmação mais sensata alude ao fato de que nenhuma dessas experiências suplantou a outra, elas convivem, embora não harmoniosamente, à espera de "consumidores". Certamente, diante da variedade, da agilidade e da rapidez que o mundo contemporâneo nos exige, o importante é formar “consumidores" inquisitivos, não receptores passivos. Felipe Muanis (2007) sugere que o mundo das letras guarda ressentimento da televisão, pois esse aparelho fatalmente transformou hábitos e impôs novas formas de representação. A provocação é interessante, mas não cabe hierarquizar as práticas culturais, elegendo as "melhores" e as "piores", pois todas estão à disposição de nossas crianças e jovens - aliás, os filmes infantis são cada vez mais sofisticados e têm mercado garantido, não só pelas crianças, mas por aqueles que fazem da criança mais próxima o seu álibi, com o objetivo de assistirem a uma matinê, sem que esse ato provoque timidez ou vergonha.

Sobre a relação entre a leitura e outras formas de comunicação, o exemplo que segue é interessante. Em duas crônicas publicadas na Folha de São Paulo, Contardo Calligaris discute sobre o sucesso das aventuras de Harry Potter. A relação entre o cinema e a produção de best sellers tem criado os 
mais distintos cenários: alguns assistem a um filme e ficam curiosos quanto ao livro que deu origem à referida saga hollywoodiana e, assim, tornam-se leitores induzidos; outros lêem um livro e esperam ansiosamente pela sua exposição no cinema. Há, ainda, aqueles que fazem apenas uma coisa ou outra: bem lêem, bem assistem ao filme, não querendo conferir as limitações e as possibilidades das artes (literatura e cinema), quando colocadas em comparação. Em tempo, há os que nem lêem e nem vão ao cinema. Entretanto, o que importa é que, entre os fãs de Harry Potter, que invadem as salas de cinema nas estreias, há leitores preocupados em saber se o filme será ou não fiel ao livro. Em ambos os textos, Contardo Calligaris nos permite apontar duas importantes questões. A primeira delas é que a leitura é praticada entre os jovens, sem que eles precisem ser obrigados a ela. Mesmo considerando que, para alguns, Harry Potter não possa ser comparável aos textos eleitos como "clássicos", ele é uma leitura e, como demonstra o psicanalista, concede aos leitores uma história que lhes empresta sentido de comunidade. Por conta disso, é possível encontrar na narrativa de Rowling os elementos do mito fundador, presentes também nos clássicos da literatura infanto-juvenil, tais como a orfandade e a vivência de aventuras miraculosas, capazes de solidificar o aprendizado necessário para a vida adulta (CALLIGARIS, 2004).

A segunda questão já foi anunciada e não me alongarei a seu respeito: sempre cambiantes, as práticas de leitura transformam-se ainda mais rapidamente no mundo contemporâneo, pois se encontram pressionadas não só por outros campos de produção artística, mas pela mudança no que se refere à sensação de passagem do tempo, à ideia de como se divertir e ao uso da tecnologia no cotidiano. Na impossibilidade de discutir tantos temas num curto espaço de tempo, gostaria apenas de apontar que a cultura contemporânea é visual e, portanto, dependente de imagens que digam, velozmente, a que vieram e, ainda mais, de imagens que consigam trazer à tona os desejos mais comuns daqueles que as observam. Não à toa, dentre outras, a publicidade é a profissão do momento, nicho onde se encontram os profissionais mais adaptados à vivência cotidiana, exigente que é da flexibilidade e da variação. Isso não significa que o livro, tal como conhecemos, vá desaparecer, mas significa que o cinema e a televisão, construtores alternativos de narrativas, seduzem e estão em acordo com as exigências contemporâneas por agilidade, rapidez e fruição. Numa única frase, pode-se anotar o "dilema”: a leitura exige relação distinta com o tempo. Um livro que virou filme é exibido, no cinema, em duas horas, no máximo, extrapolando todas as previsões, em três horas. Por mais que me considere um leitor voraz, é impossível ler um livro, tal como os que têm roteiro adaptado para o cinema, no mesmo tempo. Se o livro e o cinema representam práticas 
culturais distintas porque representam linguagens distintas, ainda assim, ambas as práticas seduzem aqueles que gostam de uma boa narrativa.

Não podem passar despercebidas duas informações: a primeira, que Monteiro Lobato era um admirador e entusiasta do cinema norte-americano e, a segunda, que sua obra infantil não teve grandes problemas em ser adaptada para a TV. A primeira adaptação do Sítio para a televisão foi feita pela TV Tupi, entre 1952 e 1962, alcançando um sucesso estrondoso. Em 1964, a TV Cultura acolheu o Sítio, mas a repercussão não foi a mesma e o programa se manteve no ar por apenas seis meses. Entre 1967 e 1969, foi a vez da TV Bandeirantes. Entretanto, a adaptação feita pela Rede Globo, entre os anos de 1976 e 1986, é a mais conhecida, sendo inesquecíveis as escolhas da música de abertura de Gilberto Gil e da atriz, que seria consagrada como a "eterna Dona Benta", querida por gerações de crianças, Zilka Salaberry. A versão do Sítio para a geração dos internautas foi introduzida pela TV Globo em 2001. Nessa adaptação, alguns exageros produzem o estranhamento: Dona Benta comunica-se com seus netos pela internet e maneja o aparelho de microondas. Nessa versão "moderníssima”, o cenário espalhafatoso e a ausência de Zilka Salaberry trazem um Sítio que contrasta com as representações anteriores, particularmente a mais conhecida dos anos de $1970 \mathrm{e}$ 1980. Mesmo considerando que adaptações não têm o estreito compromisso de fidelidade à obra, é relevante anotar a destreza da linguagem lobatiana em navegar nos mares dos produtores de narrativas alternativas.

Dito isso, não escapamos do fato conhecido de que nossos consumidores jovens querem "tudo ao mesmo tempo agora". Nos anos de 1950, mesmo pequena e monocromática, a televisão espantou o público dos cinemas - o mesmo cinema que, no início do século XX, era considerado um divertimento das classes de pouca ou nenhuma cultura. Em franca reação, a indústria cinematográfica investiu na exploração de outros recursos, capazes de seduzir ainda mais os sentidos: na corrida contra a perda de público, o som, a filmagem e a projeção passaram a receber ainda mais atenção. Em 1952, criou-se o cinema 3D, que exigia o uso de óculos para que o espectador pudesse acompanhar a cena em três dimensões (SEVCENKo, 2001, p. 81). Em síntese, nós somos seduzidos todos os dias por histórias, mesmo que os meios de sua transmissão sejam distintos. A modernidade nos tornou ouvintes, leitores, mas, sobretudo, expandiu o ambiente da cultura letrada e, com ela, as diversas formas de narrativa.

Para abandonar de vez a crença desesperada de que os leitores juvenis apenas decrescem paulatinamente, talvez seja preciso lembrar e "aceitar" que o importante é entregar-se à leitura, familiarizar-se com tal universo da leitura, 
lendo o que permite ativar o desejo de seguir lendo. Assim, além de considerarmos a leitura "certa" para a "faixa etária" (e essa não é uma descoberta minha, os educadores há muito conhecem e aplicam essa sensata norma), é preciso se livrar de um antigo preconceito que ronda as escolhas literárias. Dito de outro modo: para "formar" um leitor, é preciso conquistá-lo a essa prática e não são apenas as leituras "escolares" ou as leituras "consideradas clássicas" possuidoras de condições de "converter uma alma para a leitura". A dificuldade de admissão dessa última premissa é complicada, afinal, como anota Abreu (2006), por um lado, os livros que lemos ou dizemos ter lido constroem nossa imagem social e, nesse sentido, se queremos parecer distintos e eruditos, certamente citaremos Proust em vez de Sidney Sheldon. Entretanto, Sidney Sheldon pode muito bem, se os preconceitos forem domados, "preparar o terreno" para um leitor promissor, capaz de acessar as maravilhas na literatura de Proust ou James Joyce. Ainda sobre esse propósito, rapidamente, gostaria de fazer mais duas anotações, com cunho de parêntese.

A primeira delas é para dizer que Monteiro Lobato, à sua época, recebeu críticas de colegas importantes de profissão, como, por exemplo, Cecília Meireles. Muito ciosa à tarefa de educar crianças, a poetisa considerava Lobato "muito engraçado escrevendo", sendo seus personagens a representação do que havia de "mais malcriado e detestável no território da infância”. Ia mais longe ao comentar que, apesar de divertida, a literatura de Lobato deseducava e, portanto, arrematava que "por nenhuma fortuna do mundo eu assinaria um livro como os de Lobato, embora não deixe de os achar interessantes" (SOARES, 2005, p. 449). Mesmo que se considere o fato de a crítica extrapolar o universo literário, envolvendo distintas concepções em relação à educação e à formação, o exemplo serve para lembrar que os leitores de Lobato (adultos ou crianças) não eram necessariamente eruditos, mas liam por prazer. Essa informação serve, sobretudo, para compreendermos, de uma vez por todas, que a "boa leitura" ontem pode não ser a "boa leitura" hoje ou amanhã - e vice-versa. Lembremos, ainda, que até virar "leitura de concurso de miss", O Pequeno Príncipe era um livro tomado como uma boa leitura formadora. O mesmo ocorria com Pollyana, que formou gerações e esteve sob os cuidados da tradução e da divulgação de Monteiro Lobato. Embora ambos os livros continuem a circular no mercado editorial (com versões completamente distintas das anteriores, que cuidam do texto na tentativa de colocar o leitor em contato com um "clássico" recontado, em linguagem adequada aos tempos atuais) e ainda sejam lidos, eles não constituem mais, do ponto de vista da escolha da escola, uma leitura imprescindível. 
Relacionado ao anterior, o segundo parêntese é para não se desprezar a força e a importância da ampla rede de negociações estabelecida, de um lado, pelo crescimento do mercado editorial e, do outro, pelo desejo daqueles que podem assinar como os "críticos autorizados" em construir comunidades interpretativas, com vistas a conformar horizontes culturais. As estratégias de controle, distintas, mas historicamente utilizadas, colaboram para "definir as maneiras de ler”, bem como dizem quais são as apropriações autorizadas - nesse universo, retira-se do leitor a liberdade, nada absoluta conforme já anotado, para se apropriar da leitura, reinventando-a e mesmo subvertendo-a. Da longa e conhecida história de controle, a escola não escapa, particularmente, no momento em que empreende o esforço para convencer quanto à existência das "leituras legítimas". Ao concordar com a premissa de Márcia Abreu de que o que lemos (ou dizemos ler ou mesmo não lemos) estabelece nossa “imagem social”, é preciso imediatamente sublinhar que não somos nós os únicos responsáveis por essa imagem. Nesse sentido, os mediadores culturais e as instituições que representam, dentre elas, a escola, nos sobrepõem pela força de sua atuação. Definir e avalizar o que se lê é um meio para o exercício do poder. Em tempo, um esclarecimento a mais merece ser feito: a escola não deve deixar de exercer sua função de mediadora, mas deve exercê-la tendo em vista o fato de que ela não recebe "anjinhos do céu", desconhecedores da realidade terrestre. Crianças não são anjos, como o que aportou no Sítio, e as de hoje estão, como a Emília, cada vez mais espertas e informadas ${ }^{3}$.

Assumindo o risco da repetição, é importante reforçar que a leitura pode criar um universo de interpretações variadas, ao passo que um "roteiro de leitura" pode estabelecer "verdades anteriores" à experiência. A leitura é experiência, depende dessa demanda, não sendo possível "formar humanidade" se não houver experiência partilhada envolvida. O problema apontado aqui não é necessariamente o dos roteiros - instrumento pedagógico útil - que orientam a leitura, mas dos roteiros que, ao orientar a leitura, engessam a atividade do leitor, repassando-lhes informações básicas para que ele se transforme num conhecedor pela metade, aquele que apenas se informa (considerando a diferença entre "informação" e "conhecimento"), aquele que pode prescindir da aventura de acompanhar uma história.

A partir do exposto, posso, com tranquilidade, reforçar e defender a antiga ideia de que a relação entre livro e leitor contribui para o processo de humanização, apesar de todas as mudanças ocorridas no mundo contemporâneo. Não largamos de um livro, comemos, sonhamos e dormimos com ele, quando sentimos que, de algum modo, aquela poderia ser a nossa história. A metáfora da comida e sua associação aos livros não é casual: ela cuida de representar a 
voracidade, o desejo e a incorporação do que se lê. Monteiro Lobato não fugiu ao uso dessa metáfora: em A Reforma da Natureza, Emília, num ímpeto mudancista, transformou a biblioteca de Dona Benta em comida; todos os livros passaram a ser comestíveis e, numa mesma leitura, poderia se provar do prato principal à sobremesa. Das críticas de Dona Benta às reformas de Emília, a senhora reservou alguma simpatia à modificação dos livros. Na fala de Dona Benta, Monteiro Lobato, ao mesmo tempo, expõe uma avó adaptável às mudanças e indica a leitura como alimento, tal como a citação demonstra:

Sim, Emília, esta ideia do livro comestível me parece ótima, um verdadeiro achado. Mas não para todos os livros. O bom é que haja o livro de papel e ao seu lado o livro comestível. Quem quiser, compra um, quem quiser compra o outro. As coisas novas jamais substituem inteiramente as coisas velhas (LOBATO, 1994, p. 26).

Dessa discussão retira-se que, se como daquilo que mais gosto para matar minha fome, incorporo a leitura que mais me agrada porque ela me faz pensar, expor minhas próprias convicções, questionar meus valores. Enquanto crescemos, imaginamos, em dadas circunstâncias, como seria ter o pó de Pirlimpimpim para que, viajando a lugares mais distantes do mundo, admitamos a nossa humanidade. Sabedores do fato de que somos as únicas criaturas do planeta capazes de produzir e contar histórias, por meio delas, apostaremos em nossa capacidade de mudança e adaptação. Desse modo, há estilos distintos e histórias aos montes, entretanto, as que continuam a encantar adotam elementos representativos de uma fórmula de conquista do leitor porque lhe dá a chave de compreensão de si e da comunidade que o cerca por meio da introspecção exigida pela leitura. Com tantas histórias à disposição, vamos experimentar a aventura de discutir duas delas: Memórias de Emília, de 1939, e A Reforma da Natureza, de 1941.

\section{Emília, Emília, sempre Emília: Entre Memórias e Reformas}

Quando escreve, Monteiro Lobato brinca com a narrativa, com o tempo e com a imaginação. Cada um desses elementos aparece em seus textos de "cabeça para baixo", obrigando o leitor a se acostumar com um mundo diferente e em constante transformação. Ao final de suas histórias, quando o mundo volta ao eixo, já não se pode dizer, com certeza, que ele seja o mesmo. Assim Lobato colabora para formar "meninos e meninas moderninhos", como Pedrinho e Narizinho - o fruto mais bem acabado 
de seu ideal pedagógico. Memórias da Emília e A Reforma da Natureza são produções emblemáticas das afirmações anteriores. Da perspectiva anunciada no início deste artigo, a obra infantil de Monteiro Lobato interessa porque possibilita refletir sobre a relação entre História e Literatura e indagar a respeito da importância do texto e sua elaboração.

Não é coincidência o desejo de pensar em "memórias" e "reformas": ambas cabem no reino que confere singularidade aos indivíduos, lhes permitindo criar um gran finale para si mesmos. Nesse gran finale, poderiam se apresentar como seres "mais bem acabados". Tanto a ideia de escrever memórias quanto a ideia de reformar a natureza (que poderia ser ampliada para uma "reforma de homens", embora Emília não tenha se proposto a tanto) encerram o desejo de "melhora" do texto e da vida. Nós, leitores, confrontados com essa máxima, a adotaríamos, sem titubear: quem de nós não quer incorporar uma novidadezinha aqui, outra ali? Quem não quer assumir a possibilidade de reformar o texto da própria vida, enganando a morte, como sugere Emília?

Com tais temas, Lobato sugere, nada implicitamente, o caráter de construção do texto e a possibilidade de interação com seu leitor por meio de histórias que, embora acabadas, esperam pela inquirição das crianças. Nesse sentido, a proposta narrativa de Lobato é, simultaneamente, ordenada e desordenada. Se, por um lado, a ordem se encontra atrelada à necessidade de contar uma história, emprestando-lhe sentido, por outro, a desordem está nas inversões sem hora dessas histórias e na espera do questionamento por parte do leitor. As histórias são constituídas de um modo permissivo e, mais ainda, de modo a conduzir à inquirição. A fusão entre "real" e "fantasia" prepara o leitor para que o rumo dos acontecimentos se transforme a qualquer momento. Quem quer uma "historinha" com "começo, meio e fim", pautada pela "moral da história”, se verá frustrado pela reforma da Emília na fábula de La Fontaine. Segundo a bonequinha, o pobre fabulista apenas construiu uma fábula "que desse razão ao seu medo de mudar" (LoвATo,1994, p. 14). Com a reforma na fábula medrosa, Emília desordenou tudo, deixou um pedaço da fábula, criando "uma fábula inacabada, como aquela sinfonia famosa" (LOBATO, 1994, p. 14). A reforma na fábula, desordenando-a, aproximou-a de uma sinfonia famosa - há algo tão próximo da perfeição quanto uma sinfonia? Dessa maneira, a desordem (a retirada de um pedaço do texto, a esmo) pode ser entendida como reordenamento, demonstrando que a construção e a reconstrução guardam cada qual um papel importante no interior da elaboração de um texto.

Se em A reforma da natureza, Emília aponta que o fabulista fez apenas ordenar a fábula, deixando-a "arranjadinha", em Memórias, a Marquesa de Rabicó defende que para que o leitor faça uma alta ideia do escrevedor, 
cabe a esse último se destacar por meio da mentira bem contada, aquela que parecerá uma "verdade pura". Para que a estratégia de escrita de memórias seja convincente, duas ações são imprescindíveis, estando vinculadas entre si: arrumar as "coisas" (o texto) para conseguir enganar o leitor e apresentar-se de maneira a singularizar-se. Escrever passa a estar associado ao ato de enganar o leitor, construindo um universo lúdico. Todavia, enganar o leitor é enganar, num primeiro momento, a si mesmo, caindo na armadilha comum àqueles que resolvem contar sua vida: os indivíduos obrigam-se à produção de um projeto narrativo que inutilmente esconda os lapsos, as lacunas, as arestas.

Sabedor do ofício do escritor como "enganador", Lobato apresenta, como que para brincar com seu interlocutor, inversões surpreendentes em Memórias. Primeiro, as memórias são escritas a duas mãos: Visconde é quem começa e Emília é quem coloca um ponto final na narrativa, avisando: "se gostaram delas muito bem, se não gostaram, pílulas! Tenho dito". De imediato, o leitor é surpreendido pela confiança e liberdade depositadas pela bonequinha em Visconde - embora ela só assim procedesse porque tinha coisas mais interessantes para fazer. Visconde devia "fazer de conta" que Emília estava lhe ditando a história, enquanto a esperta conversava com Quindim. De hora em hora, ela viria conferir o escrito, solicitando a Visconde a leitura. Em determinado ponto, Sabugosa, cansado de ser explorado, resolve escrever as "suas verdades" sobre Emília e, quando a boneca chega e lhe cobra a leitura, ele tenta enganá-la. O sabugo não tem êxito, pois Emília percebe e, depois de se apoderar dos papeis, se põe a ler os trechos escritos por Visconde. No momento em que o leitor está preparado para que Emília use a borracha, ela admite a decisão acertada do Visconde: "O senhor me traiu. Escreveu aqui uma porção de coisas perversas e desagradáveis, com o fim de me desmoralizar perante o público. Mas, pensando bem, vejo que sou assim mesmo. Está certo" (LOBATO, 2002, p. 50). De um modo espantoso e pregando uma peça em quem queria lhe pregar uma, Emília singulariza-se.

$\mathrm{Na}$ sequência, Emília decide terminar suas memórias sozinha, contando sobre o que teria acontecido, colocando no passado, um futuro nunca vivenciado, a não ser na imaginação. Nesse ponto da narrativa, Lobato apresenta, sem se confundir ou confundir o leitor, três tempos: o presente daqueles que escrevem (Visconde e Emília), o passado do escrito (a confusão que o anjinho provocou, quando passou uns tempos no Sítio) e o futuro do escrito imaginado por Emília, quando a boneca se coloca em Hollywood acompanhada de Shirley Temple, Peter Pan, Alice e Visconde, dentre outros. Além do tempo rocambolesco, o encontro entre personagens, de distintas histórias (traço comum da obra infantil de Lobato) empresta ao 
leitor a sensação de que a história poderia não acabar bem - registre-se aqui que essa é a impressão de um leitor adulto, que quer saber, com ansiedade, como Lobato terminará o enredo. Desconfio que um leitor de tenra idade divirta-se a valer com tanta mistura, afinal o tempo para esse leitor ainda não é puramente sequencial (é conhecida a dificuldade das crianças com os “ontens, anteontens, amanhãs, depois de amanhãs").

Finalmente, depois de uma discussão com o Visconde, que teimava com Emília por considerar um abuso escrever em memórias aquilo que não se passou, Emília decreta que deixaria o segundo volume de suas memórias para depois, quando ficasse velha. Mais uma vez, Lobato surpreende: que delícia poder escrever memórias em dois tempos! Fica a pergunta: será que Emília faria como o seu criador, reconstruindo todo o seu escrito numa segunda leitura? Provavelmente, sim. Alterego de Lobato, Emília sabia muito bem que escrever (e ler) era remendar, refazer, reinventar, fazendo suas asneiras parecerem verdades convincentes.

Nesse ligeiro percurso, espero ter sido capaz de demonstrar a novidade que a literatura de Monteiro Lobato representou e ainda representa. Por meio de seus personagens, o autor escrevia sobre a vida e a reinventava, fazendo da imaginação e do leitor seus fieis escudeiros. Do mesmo modo, implicitamente, persegui como objetivo apontar o sentido do debate histórico contemporâneo, que é responsável pela (re) colocação da narrativa como um problema, o que leva, evidentemente, a repensar as raízes próximas e as fronteiras estabelecidas entre a História e a Literatura. Ainda pretendi apontar algumas questões referentes à formação de leitores, procurando denotar a importância da vinculação entre a leitura e o desejo, ao considerar que a leitura é mais do que uma prática mecânica porque constitui experiência desejada e partilhada. Para finalizar este texto, resta agradecer o leitor por ter alcançado o seu final, esperando que de sua leitura tenha obtido algum prazer.

\section{Literature and The Life: the teXt and the ReAders of Monteiro Lobato}

AвSTRACT: This article intends to follow the transformations of practical the cultural contemporaries, with special attention for the activities of reading and elaboration of texts. In this direction, the infantile workmanship of Monteiro Lobato will serve of guide for this quarrel, with the fast evaluation of two writings of the related author: Memories of Emília, of 1939, and the Reformation of the Nature, 1941.

KeYwords: Monteiro Lobato, History, Literature, reading. 
NOTAS

1 Como apontam os especialistas, remeto-me a autores tais como Marisa Lajolo, Regina Zilberman e Gabriela Soares, Lobato foi um crítico categórico e persistente da "correção da língua". Em seu entender, havia alto teor de artificialismo no uso empolado da linguagem, herança do português arcaico, persistente nos escritos para as crianças. Para Lobato, a naturalidade estava na incorreção, o melhor era saber escrever como se falava. O apelo a uma linguagem menos empolada demonstra que, para Lobato, era preciso aproximar a literatura da vida, concedendo ao leitor o deleite de se sentir vivo e atuante, amparado por uma obra que lhe permitisse ir ao encontro das aventuras e das emoções narradas. Sobre o romance Éramos Seis e a escrita de Dupré, Lobato comenta: "Quem fala no livro inteiro é a protagonista, a viúva, e essa boa mulher pensa e fala exatamente como todas as mulheres do seu tipo e de sua classe no país [...]. E consegue um milagre: tudo fica vida, só vida, em seu extraordinário romance [...]. E a gente fica a pensar numa coisa tremenda: se a 'literatura' não é a grande desgraça da literatura!" (SOARES, 2007, p. 208).

2 Felipe Muanis (2007), ao comentar as estatísticas sobre o ato de ler e o de assistir à televisão, anota: "Segundo uma pesquisa publicada no jornal Folha de São Paulo, [em 2004], 57\% das crianças e adolescentes de 2 a 17 anos vêem, todo dia no Brasil, pelo menos três horas de televisão. Somente 5\% não vêem TV. O contraponto com o livro é assustador: $43 \%$ das crianças não lêem livros em hora nenhuma no Brasil, o pior resultado entre os países analisados, enquanto que nos Estados Unidos 52\% lêem de uma a duas horas por dia e na China 45\% lêem a mesma quantidade. Em contraponto à televisão, $43 \%$ dos pais brasileiros ouvidos disseram que seus filhos não ocupam nada de seu tempo lendo livros ou brincando com os amigos; $79 \%$ disseram que seus herdeiros não praticam esportes coletivos; $69 \%$ afirmam que eles não usam computadores”. Disponível em: http://www.letras.ufmg.br/atelaeotexto/revistatxt/felipe2.html. Acesso em: 29/03/2008, às 10 horas.

3 Em Memórias, ficamos sabendo do anjinho capturado na Via Láctea por Emília. Sentindo-se responsável por "Flor das Alturas", Emília, em conversas intermináveis com o anjo, resolve lhe ensinar a língua, pois suas dúvidas eram muitas. Com suas metáforas, Emília deixava o anjo ainda mais confuso, pois as invencionices da boneca desafiavam os limites da língua portuguesa. Sobre a árvore, por exemplo, ela explicava: "Árvore - dizia - é uma pessoa que não fala; que vive sempre de pé no mesmo ponto; que em vez de braços tem galhos; que em vez de unhas tem folhas; que em vez de andar falando da vida alheia e 
se implicando com a gente (como os tais astrônomos), dão flores e frutas. Umas dão pitangas vermelhas; outras dão laranjas doces ou azedas - e é destas que tia Nastácia faz doces; outras como aquela enorme ali (as lições eram sempre no pomar) dão umas bolinhas pretas chamadas jabuticabas. Vamos, repita: jabu-ti-ca-ba..." (LOBATO, 2002, p. 12). O anjo, que nada sabia da vida na Terra, apesar de confuso com as explicações, as aceitava - ação muito distinta da de crianças curiosas e questionadoras.

\section{REFERÊNCIAS}

ABREU, Márcia. Cultura letrada: Literatura e leitura. São Paulo: Edunesp, 2006. BERBERT JR., Carlos Oiti. O papel do historiador na constituição do conhecimento histórico: uma análise de três perspectivas. Emblemas. Boletim do Curso de História de Catalão, v. 1, n. 3, p. 39-48, 2007.

BERBERT JR., Carlos Oiti. A história, a retórica e a crise dos paradigmas. Tese (Doutoramento do Programa de Pós-Graduação em História) - Universidade de Brasília, Brasília, 2005.

BIGNOTTO, Cilza. Monteiro Lobato em construção. Disponível em: <www.unicamp.br/iel/monteirolobato/outros/cilza01Lobato.pdf.>. Acesso em: 28 mar. 2008. 10:00

CALLIGARIS, Contardo. O segredo de Harry Potter.. In: , Terra de Ninguém. São Paulo: Publifolha, 2004, p. 50-53.

CALLIGARIS, Contardo. Os fieis de Harry Potter.. In: , Terra de Ninguém. São Paulo: Publifolha, 2004a, p. 156-159.

CALLIGARIS, Contardo. O futuro encolheu.. In: Terra de Ninguém. São Paulo: Publifolha, 2004b, p. 86-89.

CANDIDO, Antonio. A literatura e a formação do homem. Remate de Males, Revista do Departamento de Teoria Literária da Unicamp, Campinas, 1999. p. 81-113.

CHARTIER, Roger. A aventura do livro do leitor ao navegador: conversações com Jean Lebrun. São Paulo: Edunesp; Imprensa Oficial do Estado de São Paulo, 1999.

LAJOlO, Marisa; Zilberman, Regina. Literatura infantil brasileira: história e histórias. São Paulo: Ática, 1984.

LAJOLO, Marisa. Monteiro Lobato e Dom Quixote: viajantes nos caminhos da leitura. Disponível em: <www.unicamp.br/iel/monteirolobato/outros/QuixoteIEL. pdf. $>$. Acesso em: 28 mar. 2008. 10:00.

LISPECTOR, Clarice. Felicidade clandestina. In: Felicidade Clandestina: 
contos. Rio de Janeiro: Rocco, 1998. p. 9-12.

LOBATO, Monteiro. A reforma da natureza. 38. ed. São Paulo: Brasiliense, 1994.

LOBATO, Monteiro. Memórias da Emília. 42. ed. São Paulo: Brasiliense, 2002.

LOBATO, Monteiro. O Picapau Amarelo. 34. ed. São Paulo: Brasiliense, 2004.

LOBATO, Monteiro. Reinações de Narizinho. 48. Ed. São Paulo: Brasiliense, 2005.

LUCA, Tânia Regina de. Monteiro Lobato: estratégias de poder e auto-representação n' A barca de Gleyre. In: GOMES, Ângela de Castro (Org.). Escrita de si, escrita da História. Rio de Janeiro: FGV, 2004. p. 139-162.

MUANIS, Felipe. Aprendendo a ler a televisão: uma confluência possível. Disponível em: $<$ http://www.letras.ufmg.br/atelaeotexto/revistatxt/felipe2.html $>$. Acesso em: 29 mar. 2008. 10:00.

PIGLIA, Ricardo. O último leitor. São Paulo: Companhia das Letras, 2006.

SEVCENKO, Nicolau. A corrida para o século XXI: no loop da montanha russa. São Paulo: Companhia das Letras, 2001.

SOARES, Gabriela Pellegrino. Semear horizontes: uma história da formação de leitores na Argentina e no Brasil, 1915-1954. Belo Horizonte: Ed. da UFMG, 2007.

SOARES, Gabriela Pellegrino. Leopoldo Lugones, Cecília Meireles e o cultivo das leituras literárias na primeira infância. In: SCHAPOCHNIK, Nelson; ABREU, Márcia (Orgs.). Cultura letrada no Brasil: objetos e práticas. Campinas: Mercado das Letras, Associação de Leitura do Brasil (ALB); São Paulo: Fapesp, 2005. p. 435-452.

SCHAPOCHNIK, Nelson. Cultura letrada: objetos e práticas. Uma introdução. In: SCHAPOCHNIK, Nelson, ABREU, Márcia (Orgs.). Cultura letrada no Brasil: objetos e práticas. Campinas: Mercado das Letras, Associação de Leitura do Brasil (ALB); São Paulo: Fapesp, 2005. p. 9-10. 
